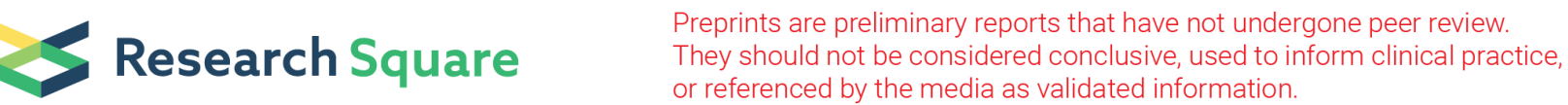

\section{Knowledge, Attitude, and Practice of Cervical Cancer Screening and Associated Factors Among Reproductive Aged Women in Ethiopia: A Meta- Analysis and Systematic Review}

Yoseph Merkeb Alamneh ( $\nabla$ ymerkeb11@gmail.com )

Debre Markos University https://orcid.org/0000-0001-7612-4809

Alehegn Aderaw Alamneh

Debre Markos university

Abtie Abebaw Shiferaw

Debre Markos University

Research article

Keywords: Knowledge; Attitude; Cervical Cancer Screening Practice; Ethiopia

Posted Date: April 24th, 2020

DOI: https://doi.org/10.21203/rs.3.rs-24245/v1

License: (c) (1) This work is licensed under a Creative Commons Attribution 4.0 International License.

Read Full License 


\section{Abstract}

Background: Cervical cancer is the leading cause of cancer deaths, accounting for $9 \%$ of female cancer deaths. In addition, more than $85 \%$ of cervical cancer related deaths are found in low and middle-income countries. Women's knowledge and attitude are barriers for the uptake of cervical cancer screening service in Ethiopia. Studies conducted on knowledge, attitude, and practice of cervical cancer screening and associated factors among reproductive age women are inconsistent. Therefore, this systematic review and meta-analysis aimed to estimate the national level of knowledge, attitude, and practice of cervical cancer screening and associated factors among women aged 15-49 years in Ethiopia.

Methods: An international database such as PubMed, EMBASE, Scopus, Google Scholar, Science Direct Cochrane library, and Grey literature databases were searched an extensively. The Preferred Reporting Items for Systematic Reviews and Meta-Analyses (PRISMA) 2009 guideline were pursued for this review. The quality of each study was assessed using Newcastle- Ottawa quality assessment tool. Stata version 14 was used to analyze the data. We have used a random effects model to estimate the pooled prevalence and odds ratio with $95 \% \mathrm{Cl}$. The possible heterogeneity between studies was assessed using Isquared $\left(I^{2}\right)$ test statistic. Egger's test was used to assess the publication bias.

Result: Eighteen studies with a total of 9, 897 women were included in this meta-analysis. The pooled national level of knowledge, attitude and practice towards cervical cancer screening among 15-49 years old aged women in Ethiopia was 40.37\% (95\% Cl: 30.09,50.66), 58.87\% (95\% Cl: 42.69,75.05) and 14.02\% (95\% Cl: 9.67,18.37) respectively. Being uneducated (OR: 3.10, 95\% Cl: 2.09,4.62), Women who had good knowledge (OR: 5.87, 95\% Cl: 2.57,13.40), Women who had positive attitude (OR: 4.20,95\% Cl: 2.86,6.16) and not being married (OR: $3.34,95 \% \mathrm{Cl}: 1.09,10.22)$ were the major factors of cervical cancer screening practice.

Conclusions and Recommendation: This review showed that the level of knowledge, attitude, and practice of cervical cancer screening among reproductive-age women in Ethiopia was relatively lower. Educational status, knowledge, attitude and marital status were statistically significant factors for cervical cancer screening practice. Hence, the health care provider needs to scale up health education and awareness creation about cervical cancer screening and early detection and prevention of cervical cancer.

\section{Background}

Cervical cancer is a cancer which affects the uterine cervix. It is the second most common cancer in women worldwide and the leading cause of cancer deaths in developing countries [1]. Though cervical cancer is largely preventable, worldwide, it is the second most common cause of death among gynecological cancers in reproductive-aged women. Cervix cancer is the major leading cause of cancerrelated death among reproductive-aged women, especially in developing countries [2, 3]. According to the Information Centre on Human Papilloma Virus (HPV) and cancer 2015, cervical cancer is a global public health problem with 527,624 new cases and 265,653 deaths annually, accounting for $9 \%$ of female 
cancer deaths [4]. According to the World Health Organization 2013 report, eighty-three percent of new cases and more than $85 \%$ of related deaths were in low and middle-income countries [5]. In East Africa, the incidence of cervical cancer was 42.7 per 100,000 women, followed by Southern Africa with 31.5 per 100,000 women [6]. In Ethiopia in 2012, an estimated 7095 new cervical cancer cases were diagnosed, and 4732 die annually [4]. Despite the increased prevalence of cervical cancer in developing countries, cervical cancer screening awareness is generally low. Cervical cancer is diagnosed at an advanced stage of the disease. This is because of lack of screening and early detection services. [7, 8]. High prevalence of HPV infection, low knowledge and awareness about cervical cancer, having multiple sexual partners, early onset of sexual activity, a history of sexually transmitted diseases (STDs), socioeconomic factors, biological factors (e.g. immune compromisation), poor treatment and supportive care infrastructures about cervical cancer and its screening tests are the contributing factors for the high burden of cervical cancer in Sub Saharan Africa (SSA) [2, 9]. In developed countries, a considerable reduction in cervical cancer incidence and deaths achieved by effective screening programs. However, cervical cancer is remaining the major leading cause of morbidity and mortality following breast cancer among women in limited-resource countries, including Ethiopia. This is mainly because of poor systematic screening practice, limited access to health services and labs, no screening programs, limited or non-existent awareness among populations and health workers, limited or no access to diagnostics and laboratories, poor referral and follow up [10]. In Ethiopia, the Federal Minister of Health (FMOH) launches guidelines for cancer control plan which aims to provide an information for healthcare providers, implementing partners and other stakeholders involved in the prevention and control of cervical cancer. The program is aimed to decrease the incidence of cervical cancer by $15 \%$ by 2020 [11]. However, still, there is scanty information regarding the knowledge, attitude, and practices of cervical cancer screening. Only $0.6 \%$ of eligible women were screened for cervical cancer $[2,12]$. Cervical cancer screening coverage in developing countries is about (19\%), in developed countries (63\%) [13]. Despite this fact, there is still a gap in knowledge, attitude, and practice of cervical cancer screening in Ethiopia [14]. Women's knowledge and attitude on cervical cancer determine the uptake of service for screening [15].

In Ethiopia, contradicted studies have been conducted to assess knowledge, attitude, and practice of cervical cancer screening and associated factors among women aged 15-49 years in Ethiopia. The gap is still higher and with abundant discrepancy and inconstancy across regions related to the knowledge, attitude, and practice of cervical cancer screening and associated factors. So that assessing the pooled prevalence of knowledge, attitude, and practice of cervical cancer screening and its associated factors at a national level is essential and will provide a pooled estimation. Therefore, this review aimed to assess knowledge, attitude, and practice of cervical cancer screening and associated factors among women aged 15-49 years in Ethiopia. The findings of this study will be used for policymakers and program planners who work on the area to promote, plan, implement and evaluate cervical cancer screening services and strategies. The study also will provide baseline information for future researchers.

\section{Materials And Methods}




\section{Study design and setting}

A systematic review and meta-analysis were conducted to assess knowledge, attitude, and practice of cervical cancer screening and associated factors among women aged 15-49 years in Ethiopia. Ethiopia is located in the horn of Africa. It is bounded by Eritrea to the north, Djibouti, and Somalia to the east, Sudan and South Sudan to the west, and Kenya to the south[16].

\section{Search Strategies}

The Preferred Reporting Items for Systematic Reviews and Meta-Analysis (PRISMA) guideline was used to confirm the scientific accuracy [17]. We searched articles without any limit to the date of publication and study design from the major databases such as PubMed/MEDLINE, Web of Science, EMBASE, CINAHL, Google Scholar, Science Direct and Cochrane Library. EndNote (version X7) reference management software was used to download, organize, review and cite the articles. This review included all articles published in peer-reviewed journals, that were written in the English language. [18]. Also, Gray literature of observational studies and official websites of international and local organizations and universities were searched. The search of the literature was conducted from the 1st of September, 2019 to the 1st of December, 2019. All papers published until the 1st of December, 2019 were considered. The Electronic databases were searched by medical subject headings $(\mathrm{MeSH})$ terms and using the following keywords: "Knowledge", "Attitude", "Practice”, "cervical cancer", "and 15-49 years old women”, "barriers", "determinants", "associated factors and Ethiopia". We used the search terms independently and/or in combination using Boolean operators like "OR" or "AND".

\section{Eligibility Criteria}

\section{Inclusion criteria}

\section{Study area}

Studies conducted only in Ethiopia were considered.

\section{Population}

Only studies involving reproductive age women (15-49 years old women) were included.

\section{Publication condition}

Both published and unpublished articles were included.

\section{Study design}


All observational study designs (i.e., cross-sectional) reporting the knowledge, attitude, and practice of screening cervical cancer among reproductive age groups of women were included.

\section{Language}

Articles reported only in English language were considered.

\section{Exclusion criteria}

Articles, which were not fully accessible and not reported the outcome of interest, after at least two-email contact with the primary authors, were excluded.

\section{Measurement of outcome variables}

The main outcome of this study was to assess the pooled levels of knowledge, Knowledge, Attitude, and Practice of Cervical Cancer Screening and Associated Factors.

\section{Data Extraction And Quality Assessment}

Data were extracted using a standardized data extraction spreadsheet format in Microsoft Excel. The data abstraction format includes author/s name, year of publication, study region, study design, sample size, the prevalence of knowledge, prevalence of attitude and prevalence of cervical cancer practice. All published and unpublished primary studies in the English language, conducted at the community or health institution level from 2015 to December 2019 were included. The data were extracted by three independent authors (YM, AAS, and AA). Joanna Briggs Institute (JBI's) critical appraisal checklist for prevalence studies was used to assess the quality of included studies [19]. Additionally, a modified version of the Newcastle-Ottawa Scale (NOS) was used to assess the methodological quality of studies for cross-sectional studies [20]. Newcastle -Ottawa scale criteria include representativeness of the sample, response rate, measurement tool used, comparability of the subject, appropriateness of the statistical test used to analyze the data. Based on the Newcastle -Ottawa scale criteria, two authors (YM and $A A$ ) independently assessed the quality of each article. Whenever necessary, another reviewer (AAS) was involved and any discrepancy was resolved through discussion and consensus.

\section{Data Processing And Analysis}

For farther analysis, we imported the data to STATA version 14.0 statistical software after extracting the data using Microsoft Excel format. We identify the heterogeneity between the studies using Cochrane's $Q$ statistics (Chi-square), inverse variance $\left(I^{2}\right)$ and $p$-values [21]. As the test statistic showed there is significant heterogeneity among the studies (Fig. 2A, 2B and 2C) as a result a random-effects metaanalysis model was used to estimate the DerSimonian and Laird's pooled effect. In the current meta- 
analysis, arcsine-transformed proportions were used. The pooled proportion was estimated by using the back-transform of the weighted mean of the transformed proportions, using arcsine variance weights for the fixed-effects model and DerSimonian-Laird weights for the random-effects model [22]. Egger's and Begg's tests, with the p-value, less than $5 \%$ was used to declare the presence of publication bias [23]. Also, using forest plot, point prevalence, as well as $95 \%$ confidence intervals, was presented. In this plot, the size of each box indicated the weight of the study, while each crossed line refers to a $95 \%$ confidence interval. For the second outcome, a log odds ratio was used to determine the association between determinant factors and cervical cancer screening among 15-49 years old women.

\section{Study Selection And Data Extraction}

This systematic review and meta-analysis have been reported by the preferred reporting items for systematic reviews and meta-analyses (PRISMA) statement [24]. Initially, 455 articles related to KAP of cervical cancer screening were found. Of these, 168 duplications and 263 unrelated articles were excluded. Second, from the remaining 24 potential articles, 18 met eligibility for the review and included in the analysis. Six full-text articles were excluded due to did not meet outcomes of interest or study area (Fig. 1).

\section{Characteristics of included studies}

Eighteen studies with a total sample of 9, 897 women (aged 15-49 years old) were included in this systematic review and meta-analysis. The main characteristics of the included studies are described in Table 1. 
Table 1

Characteristics of the included studies in the meta-analysis in Ethiopia, 2019

\begin{tabular}{|c|c|c|c|c|c|c|c|}
\hline SN & Author & Year & Region & Study area & Study design & $\begin{array}{l}\text { Sample } \\
\text { size }\end{array}$ & $\begin{array}{l}\text { Quality } \\
\text { Score }\end{array}$ \\
\hline 1 & $\begin{array}{l}\text { Shiferaw et } \\
\text { al }\end{array}$ & 2018 & $\begin{array}{l}\text { Addis } \\
\text { Ababa }\end{array}$ & $\begin{array}{l}\text { Addis } \\
\text { Ababa }\end{array}$ & $\begin{array}{l}\text { cross- } \\
\text { sectional }\end{array}$ & 581 & High \\
\hline 2 & $\begin{array}{l}\text { Getachew et } \\
\text { al }\end{array}$ & 2019 & $\begin{array}{l}\text { Addis } \\
\text { Ababa }\end{array}$ & $\begin{array}{l}\text { Addis } \\
\text { Ababa }\end{array}$ & $\begin{array}{l}\text { cross- } \\
\text { sectional }\end{array}$ & 520 & High \\
\hline 3 & Kalau et al & 2018 & Amhara & $\begin{array}{l}\text { Debre } \\
\text { Berhan }\end{array}$ & $\begin{array}{l}\text { cross- } \\
\text { sectional }\end{array}$ & 578 & Moderate \\
\hline 4 & Kasa et al & 2018 & Amhara & $\begin{array}{l}\text { Finote } \\
\text { Selam }\end{array}$ & $\begin{array}{l}\text { cross- } \\
\text { sectional }\end{array}$ & 735 & Moderate \\
\hline 5 & Mesfin et al & 2017 & $\begin{array}{l}\text { Addis } \\
\text { Ababa }\end{array}$ & $\begin{array}{l}\text { Addis } \\
\text { Ababa }\end{array}$ & $\begin{array}{l}\text { cross- } \\
\text { sectional }\end{array}$ & 508 & High \\
\hline 6 & $\begin{array}{l}\text { Tsegaye et } \\
\text { al }\end{array}$ & 2018 & SNNP & Hawassa & $\begin{array}{l}\text { cross- } \\
\text { sectional }\end{array}$ & 380 & High \\
\hline 7 & Gebrie et al & 2015 & $\begin{array}{l}\text { Addis } \\
\text { Ababa }\end{array}$ & $\begin{array}{l}\text { Addis } \\
\text { Ababa }\end{array}$ & $\begin{array}{l}\text { cross- } \\
\text { sectional }\end{array}$ & 275 & High \\
\hline 8 & Worku et al & 2018 & Oromia & Bishoftu & $\begin{array}{l}\text { cross- } \\
\text { sectional }\end{array}$ & 845 & High \\
\hline 9 & Assefa et al & 2015 & Amhara & Dessie & $\begin{array}{l}\text { cross- } \\
\text { sectional }\end{array}$ & 660 & High \\
\hline 10 & Zelalem et al & 2018 & Amhara & Gonda & $\begin{array}{l}\text { cross- } \\
\text { sectional }\end{array}$ & 267 & High \\
\hline 11 & $\begin{array}{l}\text { Geremew et } \\
\text { al }\end{array}$ & 2018 & Amhara & $\begin{array}{l}\text { Finote } \\
\text { Selam }\end{array}$ & $\begin{array}{l}\text { cross- } \\
\text { sectional }\end{array}$ & 1137 & Moderate \\
\hline 12 & Bulto et al & 2019 & Oromia & Shoa & $\begin{array}{l}\text { cross- } \\
\text { sectional }\end{array}$ & 423 & Moderate \\
\hline 13 & Dulla et al & 2017 & SNNP & Hawassa & $\begin{array}{l}\text { cross- } \\
\text { sectional }\end{array}$ & 367 & High \\
\hline 14 & Atif et al & 2019 & Oromia & Jimma & $\begin{array}{l}\text { cross- } \\
\text { sectional }\end{array}$ & 154 & High \\
\hline 15 & Tilahun et al & 2019 & Oromia & Wollega & $\begin{array}{l}\text { cross- } \\
\text { sectional }\end{array}$ & 805 & Moderate \\
\hline 16 & Aweke et al & 2017 & SNNP & Hadiya & $\begin{array}{l}\text { cross- } \\
\text { sectional }\end{array}$ & 583 & High \\
\hline 17 & Assefa et al & 2019 & SNNP & Hawassa & $\begin{array}{l}\text { cross- } \\
\text { sectional }\end{array}$ & 342 & High \\
\hline
\end{tabular}




\begin{tabular}{|c|ccccccc|}
\hline SN & Author & Year & Region & Study area & Study design & $\begin{array}{l}\text { Sample } \\
\text { size }\end{array}$ & $\begin{array}{l}\text { Quality } \\
\text { Score }\end{array}$ \\
\hline 18 & $\begin{array}{l}\text { Nigussie et } \\
\text { al }\end{array}$ & 2019 & Oromia & Jimma & $\begin{array}{l}\text { cross- } \\
\text { sectional }\end{array}$ & 737 & Moderate \\
\hline
\end{tabular}

\section{Meta-analysis}

\section{Level of knowledge, attitude, and practice towards cervical cancer screening among 15-49 years old aged women in Ethiopia}

Overall, the pooled level of good knowledge about cervical cancer screening among 15-49 years old women in Ethiopia was $40.37 \%$ (95\% Cl: $30.09-50.66)$. The lowest was $(9.60 \%)$ and the highest was (86.90\%) (Fig. 2A). The pooled level of good attitude towards cervical cancer screening among 1549 years old women in Ethiopia was $58.87 \%$ (95\% Cl: $42.69-75.05)$. The lowest was (37.00\%) and the highest was (94.10\%) (Fig. 2B). The pooled prevalence of cervical cancer screening practice among 1549 years old women in Ethiopia was $14.02 \%$ (95\% Cl: 9.67-18.37). The lowest was (2.10\%) and the highest was (40.10\%) (Fig. 2C).

\section{Heterogeneity And Publication Bias}

The presence of publication bias was examined using visual inspection of the funnel plot and Egger's test. Visual inspection of the funnel plot suggested asymmetrical distribution of included studies. We also observed publication bias in practice of cervical cancer screening using both Begg's and Egger's tests $[25,26]$ and these tests showed that there was statistical evidence of publication bias at p-value less than 0.05 and the funnel plot was asymmetry. By consideration of publication bias trim and fill metaanalysis [31] were done. However, based on this analysis no significant change was shown as compared with the main meta-analysis. Moreover, the result of sensitivity analyses using the random-effects model suggested that none of the studies included influence the overall estimate. Given that the result of this meta-analysis revealed statistically significant heterogeneity among studies, we performed a subgroup analysis by region to adjust and minimize heterogeneity (Fig. 3).

\section{Meta-regression}

Besides subgroup analysis and publication bias, univariate and categorical meta-regression analysis was performed undertaken by considering both continuous and categorical data for the included studies to identify sources of for heterogeneity for the pooled prevalence. In meta-regression analysis, Sample size, 
publication year and study regions were considered for each study. However, there was no statistical significance value from the meta-regression analysis (Table 2).

Table 2

Meta-Regression of Knowledge, Attitude, and Practice of Cervical Cancer Screening in Ethiopia, 2019

\begin{tabular}{|c|c|c|c|c|}
\hline Domain & Variables & Characteristics & Coefficient & P-value \\
\hline \multirow[t]{6}{*}{ Knowledge } & Year & Publication & -.6734893 & 0.893 \\
\hline & Sample size & Included & -.0029275 & 0.894 \\
\hline & \multirow[t]{4}{*}{ Region } & Amhara & 3.45085 & 0.879 \\
\hline & & Addis Ababa & 6.844267 & 0.742 \\
\hline & & SNNP & 39.88295 & 0.099 \\
\hline & & Oromia & Reference & Reference \\
\hline \multirow[t]{6}{*}{ Attitude } & Year & Publication & 2.958676 & 0.662 \\
\hline & Sample size & Included & -.0098279 & 0.785 \\
\hline & \multirow[t]{4}{*}{ Region } & Amhara & -13.77482 & 0.338 \\
\hline & & Addis Ababa & 34.56641 & 0.111 \\
\hline & & SNNP & .7496539 & 0.960 \\
\hline & & Oromia & Reference & Reference \\
\hline \multirow[t]{6}{*}{ Practice } & Year & Publication & 1.221513 & 0.619 \\
\hline & Sample size & Included & -.0293279 & 0.117 \\
\hline & \multirow[t]{4}{*}{ Region } & Amhara & Reference & Reference \\
\hline & & Addis Ababa & 11.36227 & 0.274 \\
\hline & & Oromia & -.0293008 & 0.998 \\
\hline & & SNNP & 12.37763 & 0.237 \\
\hline
\end{tabular}

\section{The associated factor of the utilization of screening cervical cancer among reproductive age groups in Ethiopia}

In this meta-analysis, the association between the practice of screening cervical cancer and the educational status of women had been seen using eight studies conducted in Ethiopia. The Mataanalysis of these eight studies revealed that the practice of screening cervical cancer among reproductive-age women was significantly associated with the educational status of women (OR: 3.10, 
$95 \% \mathrm{Cl}: 2.09-4.62)$. Specifically, the likelihood of cervical cancer screening practice was 3.10 times higher among literate women compared to their counterparts. The test result of this meta-analysis revealed a significant heterogeneity among eight studies $\left(I^{2}=78.0 \%, P \leq 0.001\right)$. So the random effect meta-analysis model was used to see the association educational status with cervical cancer practice in Ethiopia (Fig. 3A). In this meta-analysis, women who had good Knowledge status about cervical cancer was found to be significantly associated with cervical cancer screening practice (OR: $5.87,95 \%$ Cl: $2.57-$ 13.40). Reproductive age women who had good knowledge about cervical cancer screening were around six times more likely to practice cervical cancer screening compared to those women who did not hear about Cervical cancer screening (Fig. 3B). In this meta-analysis, the association between the practice of screening cervical cancer and women who had a positive attitude towards cervical cancer screening had been seen using six studies conducted in Ethiopia. The Mata-analysis of these six studies revealed that the practice of screening cervical cancer among reproductive-age women was significantly associated with women who had a positive attitude towards cervical cancer screening (OR: 4.20,95\% Cl: 2.86-6.16) (Fig. 3C). This review revealed that the practice of screening cervical cancer among reproductive-age women was significantly associated with women who not being married (OR: 3.34, 95\% Cl: 1.09-10.22) (Fig. 3D).

\section{Discussion}

In Ethiopia, FMOH launches guidelines for cancer control plan which aims to provide healthcare providers, implementing partners and other stakeholders involved in the prevention and control of cervical cancer incidence and mortality by $15 \%$ by 2020 [11]. Despite this fact, there is still a gap in knowledge, attitude, and practice of cervical cancer screening in Ethiopia [14]. To our knowledge, this systematic review and meta-analysis are the first to estimate the pooled level of knowledge, attitude, and practice of cervical cancer screening among15-49 years old aged women in Ethiopia. As a result, this meta-analysis was intended to estimate the pooled level of knowledge, attitude, and practice of cervical cancer screening among $15-49$ years old aged women in Ethiopia. Besides, we have also seen the determinant factors affecting the practice of cervical cancer screening. The finding of this systematic review and meta-analysis showed that the pooled level of knowledge, attitude and practice towards cervical cancer screening among 15-49 years old aged women in Ethiopia was $40.37 \%$ (95\% Cl: $30.09-50.66), 58.87 \%$ (95\% Cl: 42.69-75.05) and 14.02\% (95\% Cl: 9.67-18.37) respectively (Fig. 2A, 2B and 2C). Educational status of women, knowledge status about cervical cancer, attitude towards cervical cancer women who heard about Cervical cancer and marital status of women were significantly associated with the practice of cervical cancer screening. The KAP towards cervical cancer screening in Ethiopia was lower compared to the other sub-Sahara African countries such as Republic of Congo (81.9\%) and in Botswana (77\%), and in China (70.2\%) [27-29] in awareness, in Chinese (80.8\%) [29], in South Africa 64.0\% [30] in Knowledge and Kenya 22\% [31], in Tanzania 14\% [32], in Malaysia 6\% [33], in Tanzania (22.6\%) [34], in Qatar 40\% [35], in India, 85\% [36] in practice of cervical cancer screening. But it was higher the study done in Nigeria $26.85 \%[37]$. This variation might be justified by the extent of the studies and differences in the health service, socio-demographic characteristics of study participants and setting and study period. The 
educational status of women was also found to be a significant predictor for cervical cancer screening practice. Specifically, literate women were around three times more likely to practice cervical cancer screening compared to their counterparts. This systematic review and meta-analysis were supported by findings of other studies conducted in Qatar [35], India [38] Congo [28]. These studies acknowledged that maternal education was a significant predictor of cervical cancer screening practice, in which women with higher educational levels will be more conscious of the importance of cervical cancer screening. In this meta-analysis, women who had good Knowledge status about cervical cancer was found to be significantly associated with cervical cancer screening practice. Reproductive age women who heard about Cervical cancer were around six times more likely to practice cervical cancer screening compared to those women who did not hear about Cervical cancer screening. This review was supported by findings of other studies conducted in by LAO PDR study [39], in Thailand 81.8\% [40], Nigerian 26.85\% [37], Iran 45.4\% [41], Kuwait 52.3\% [42]. Among women who have ever heard about cervical cancer screening were around six times more likely to practice cervical cancer screening compared to those women who did not hear about cervical cancer screening. These findings were supported the other studies done in South Africa $42.9 \%$ [43], Ukraine $80 \%[44]$. This review revealed that the practice of screening cervical cancer among reproductive-age women was significantly associated with women who not being married. Our findings have supported by a study done in Malaysia [33]. The possible explanation could be explained as single women are more likely to be younger and more exposed to sexual education and women who were single had a greater knowledge of cervical cancer screening than those who were married. Additionally, a positive attitude was a significant predictor for cervical cancer screening practice. This review findings was inconsistence with the studies done in India 83.8\% [45], in Iran 96.5\% [41], Kuwaiti $30.6 \%$ [42]. The variation may be due to study population, knowledge and educational status, availability and expansion of alternative information sources, advocacy and promotion activities of cervical cancer screening by health care providers may be better or initiated earlier and socio-economic difference.

\section{Limitations Of The Study}

One of the limitations of this systematic review and meta-analysis was only studies written by the English language were included for the pooled estimate.

\section{Conclusions And Recommendation}

This review showed that the level of knowledge, attitude, and practice of cervical cancer screening among reproductive-age women in Ethiopia was relatively lower as compared to those reported by other studies done in different countries. Educational status, knowledge, attitude and marital status were statistically significant predictors for cervical cancer screening practice among reproductive-age women in Ethiopia. Hence, the health care provider needs to scale up health education and awareness creation about cervical cancer screening and early detection and prevention of cervical cancer.

\section{Abbreviations}


YM: Yoseph Merkeb; AA: Alehegn Aderaw; AAS: Abtie Abebaw Shiferaw Cl: Confidence interval; OR: Odds Ratio; SNNP: South Nations Nationalities Peoples; KAP: Knowledge, Attitude, Practice; HPV: Human papilloma virus

\section{Declarations}

\section{Ethics approval and consent to participate}

Not applicable

\section{Consent for publication}

Not applicable

\section{Availability of data and material}

The datasets analyzed during the current study are available from the corresponding author upon reasonable request.

\section{Competing interests}

We have confirmed that we have no competing interests.

\section{Funding}

No funding was obtained for this study.

\section{Authors' contributions}

YM and AA: developed the study design and protocol, literature review, selection of studies, quality assessment, data extraction, statistical analysis, interpretation of the data and developing the initial drafts of the manuscript.

YM and AA: Involved in statistical analysis and interpretation, quality assessment, prepared the final draft of the manuscript. All authors read and approved the final manuscript

\section{Acknowledgments}

we gratefully thank the primary authors of the included studies.

\section{Authors information}

${ }^{1}$ Department of Biomedical Sciences School of Medicine, Debre Markos University, Debre Markos, Ethiopia. 
${ }^{2}$ Department of Human Nutrition and Food Sciences, College of Health Sciences, Debre Markos University, Ethiopia

${ }^{3}$ Department of medical laboratory, College of Health Science, Debre Markos University, Debre Markos, Ethiopia

\section{References}

1. Ferlay J: Cancer incidence, mortality and prevalence worldwide. GLOBOCAN20022004.

2. Getahun F, Mazengia F, Abuhay M, Birhanu Z: Comprehensive knowledge about cervical cancer is low among women in Northwest Ethiopia. BMC cancer 2013, 13(1):2.

3. Eke N, Ezeama C, Eke C, Eleje G, Akabuike J, Ezebialu I: Knowledge of Cervical Cancer and its Screening Amongst Female Workers In Nnewi, Nigeria. Afrimedic Journal 2010, 1(1):31-36.

4. Bruni L, Barrionuevo-Rosas L, Albero G, Aldea M, Serrano B, Valencia S, Brotons M, Mena M, Cosano R, Muñoz J: ICO information centre on HPV and cancer (HPV Information Centre). Human papillomavirus and related diseases in the world Summary Report 2015, 4(08).

5. Parkhurst JO, Vulimiri M: Cervical cancer and the global health agenda: insights from multiple policyanalysis frameworks. Global public health 2013, 8(10):1093-1108.

6. Organization WH: Annual technical report: 2013: department of reproductive health and research, including UNDP/UNFPA/WHO/World Bank Special Programme of Research Training in Human Reproduction (HRP). In.: World Health Organization; 2014.

7. Smith RA, Cokkinides V, Brooks D, Saslow D, Shah M, Brawley OW: Cancer screening in the United States, 2011: A review of current American Cancer Society guidelines and issues in cancer screening. CA: a cancer journal for clinicians 2011, 61(1):8-30.

8. Emanuel GO, Adesola BO, Oluwole KA, Mathew AS, Toyin EO, Aishatu O: Awareness and Practice of Cervical Cancer Screening among Women Accessing Care in a Rural Tertiary Hospital in Nigeria. Clin Med Res 2015, 4(4):120.

9. Goodwin TM, DeCherney A, Nathan L, Laufer N: Current diagnosis and treatment obstetrics and gynecology. In.: McGraw-Hill Medical; 2012.

10. Lataifeh I, Amarin Z, Khader Y: A survey of the knowledge and attitude of Jordanian obstetricians and gynaecologists to cervical cancer screening. Journal of Obstetrics and Gynaecology 2009, 29(8):757-760.

11. Loutfı A, Pickering J: The distribution of cancer specimens from two pathology centres in Ethiopia. Ethiopian medical journal 1992, 30(1):13-17.

12. Kress CM, Sharling L, Owen-Smith AA, Desalegn D, Blumberg HM, Goedken J: Knowledge, attitudes, and practices regarding cervical cancer and screening among Ethiopian health care workers. International journal of women's health 2015, 7:765. 
13. Gakidou E, Nordhagen S, Obermeyer Z: Coverage of cervical cancer screening in $\mathbf{5 7}$ countries: low average levels and large inequalities. PLoS medicine 2008, 5(6):e132.

14. Waktola EA, Mihret W, Bekele L: HPV and burden of cervical cancer in east Africa. Gynecologic oncology 2005, 99(3):S201-S202.

15. Bayu $\mathrm{H}$, Berhe $Y$, Mulat $A$, Alemu A: Cervical cancer screening service uptake and associated factors among age eligible women in Mekelle Zone, Northern Ethiopia, 2015: a community based study using health belief model. PloS one 2016, 11(3):e0149908.

16. ETHIOPIA Location \& Size: Geography - OSU http://u.osu.edu/ockerman.2/files/2014/03/Ethiopia1i7cwe5.pdf.

17. Liberati A, Altman DG, Tetzlaff J, Mulrow C, Gøtzsche PC, loannidis JP, Clarke M, Devereaux PJ, Kleijnen J, Moher D: The PRISMA statement for reporting systematic reviews and meta-analyses of studies that evaluate health care interventions: explanation and elaboration. PLoS medicine 2009, 6(7):e1000100.

18. Moher $D$, Pham B, Lawson M, Klassen $T$ : The inclusion of reports of randomised trials published in languages other than English in systematic reviews. Health Technol Assess 2003, 7(41):1-90.

19. Munn Z, Moola S, Riitano D, Lisy K: The development of a critical appraisal tool for use in systematic reviews addressing questions of prevalence. International journal of health policy and management 2014, 3(3):123.

20. Modesti PA, Reboldi G, Cappuccio FP, Agyemang C, Remuzzi G, Rapi S, Perruolo E, Parati G:

Panethnic differences in blood pressure in Europe: a systematic review and meta-analysis. PloS one 2016, 11(1):e0147601.

21. Rücker G, Schwarzer G, Carpenter JR, Schumacher M: Undue reliance on I 2 in assessing heterogeneity may mislead. BMC medical research methodology 2008, 8(1):79.

22. Nyaga VN, Arbyn M, Aerts M: Metaprop: a Stata command to perform meta-analysis of binomial data. Archives of Public Health 2014, 72(1):39.

23. Borenstein M, Hedges LV, Higgins JP, Rothstein HR: A basic introduction to fixed-effect and randomeffects models for meta-analysis. Research synthesis methods 2010, 1(2):97-111.

24. Moher D, Shamseer L, Clarke M, Ghersi D, Liberati A, Petticrew M, Shekelle P, Stewart LA: Preferred reporting items for systematic review and meta-analysis protocols (PRISMA-P) 2015 statement. Systematic reviews 2015, 4(1):1.

25. Begg CB, Mazumdar M: Operating characteristics of a rank correlation test for publication bias. Biometrics 1994:1088-1101.

26. Egger M, Smith GD, Schneider M, Minder C: Bias in meta-analysis detected by a simple, graphical test. Bmj 1997, 315(7109):629-634.

27. Mingo AM, Panozzo CA, DiAngi YT, Smith JS, Steenhoff AP, Ramogola-Masire D, Brewer NT: Cervical cancer awareness and screening in Botswana. International Journal of Gynecologic Cancer 2012, 22(4):638-644. 
28. Ali-Risasi C, Mulumba P, Verdonck K, Broeck DV, Praet M: Knowledge, attitude and practice about cancer of the uterine cervix among women living in Kinshasa, the Democratic Republic of Congo. BMC women's health 2014, 14(1):30.

29. Hong Y, Zhang C, Li X, Lin D, Liu Y: HPV and cervical cancer related knowledge, awareness and testing behaviors in a community sample of female sex workers in China. BMC Public Health 2013, 13(1):696.

30. Hoque ME: Cervical cancer awareness and preventive behaviour among female university students in South Africa. Asian Pac J Cancer Prev 2010, 11(1):127-130.

31. Gichangi P, Estambale B, Bwayo J, Rogo K, Ojwang S, Opiyo A, Temmerman M: Knowledge and practice about cervical cancer and Pap smear testing among patients at Kenyatta National Hospital, Nairobi, Kenya. International Journal of Gynecologic Cancer 2003, 13(6):827-833.

32. John J: The knowledge, attitude, practice and perceived barriers towards screening for premalignant cervical lesions among women aged 18years and above, in Songea urban, Ruvuma. Muhimbili University of Health and Allied Sciences; 2011.

33. Al-Naggar RA, Low W, Isa ZM: Knowledge and barriers towards cervical cancer screening among young women in Malaysia. Asian Pac J Cancer Prev 2010, 11(4):867-873.

34. Lyimo FS, Beran TN: Demographic, knowledge, attitudinal, and accessibility factors associated with uptake of cervical cancer screening among women in a rural district of Tanzania: three public policy implications. BMC public health 2012, 12(1):22.

35. Al Meer F, Aseel M, Al Khalaf J, Al Kuwari M, Ismail M: Knowledge, attitude and practices regarding cervical cancer and screening among women visiting primary health care in Qatar. 2011.

36. Anantharaman V, Sudharshini S, Chitra A: A cross-sectional study on knowledge, attitude, and practice on cervical cancer and screening among female health care providers of Chennai corporation, 2013. Journal of Academy of Medical Sciences 2012, 2(4):124.

37. Obiechina N, Mbamara S: Knowledge attitude and practice of cervical cancer screening among sexually active women in Onitsha, southeast Nigeria. Nigerian journal of medicine: journal of the National Association of Resident Doctors of Nigeria 2009, 18(4):384-387.

38. Bansal AB, Pakhare AP, Kapoor N, Mehrotra R, Kokane AM: Knowledge, attitude, and practices related to cervical cancer among adult women: A hospital-based cross-sectional study. Journal of natural science, biology, and medicine 2015, 6(2):324.

39. Sichanh C, Fabrice Q, Chanthavilay P, Diendere J, Latthaphasavang V, Longuet C, Buisson Y: Knowledge, awareness and attitudes about cervical cancer among women attending or not an HIV treatment center in Lao PDR. BMC cancer 2014, 14(1):161.

40. Nganwai P, Truadpon P, Inpa C, Sangpetngam B, Mekjarasnapa M, Apirakarn M, Chumworathayi B: Knowledge, attitudes and practices vis-a-vis cervical cancer among registered nurses at the Faculty of Medicine, Khon Kaen University, Thailand. Asian Pac J Cancer Prev 2008, 9(1):15-18.

41. HADI N, Azimirad A: Knowledge attitude and practice of women in Shiraz about cervical cancer and Pap smear 2009. 2010. 
42. Al Sairafi M, Mohamed FA: Knowledge, attitudes, and practice related to cervical cancer screening among Kuwaiti women. Medical Principles and Practice 2009, 18(1):35-42.

43. Hoque $E$, Hoque $M$ : Knowledge of and attitude towards cervical cancer among female university students in South Africa. Southern African Journal of Epidemiology and Infection 2009, 24(1):21-24.

44. Tsegaye S, Mengistu D, Gultie T: Knowledge and attitude towards cervical cancer screening and associated factors among female Hawassa university college of medicine and health sciences students. MOJ Public Health 2018, 7(3):151-158.

45. Varadheswari T, Dandekar RH, Sharanya T: A study on the prevalence and KAP regarding cervical cancer among women attending a tertiary care hospital in Perambalur. International Journal of Preventive Medicine Research 2015, 1(3):71-78.

\section{Figures}

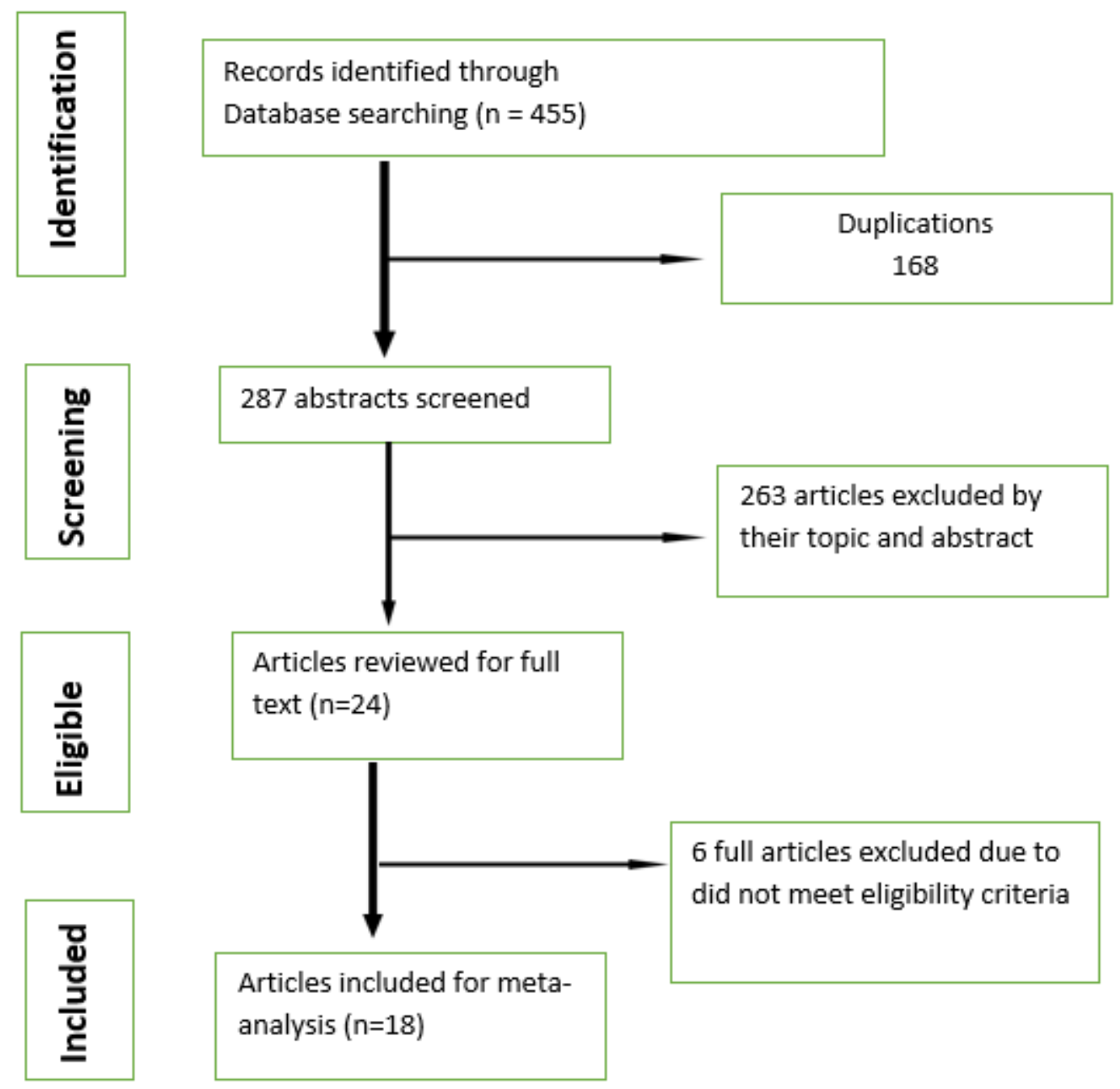

Figure 1

PRISMA flow diagram of KAP of cervical cancer screening in Ethiopia, 2019 
A

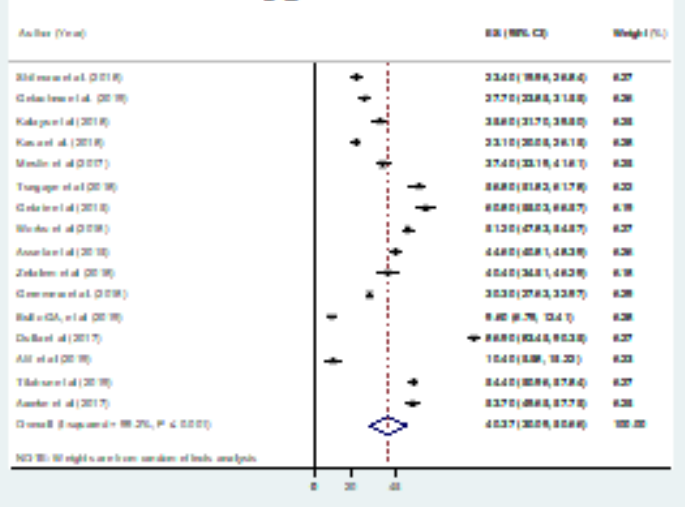

B

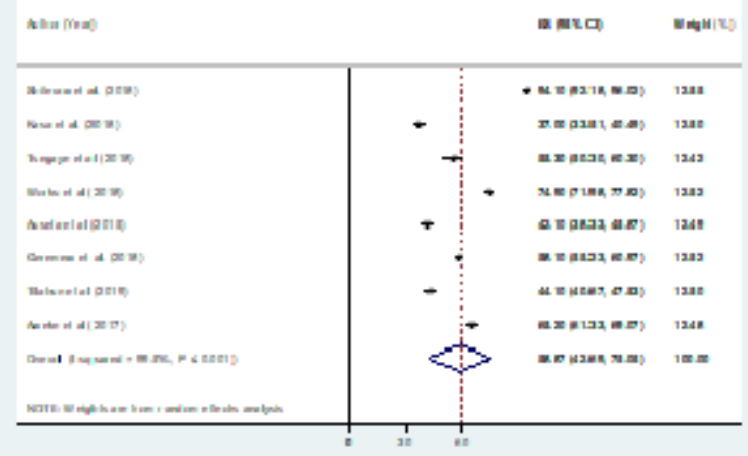

$\mathrm{C}$

\begin{tabular}{|c|c|c|c|}
\hline \multicolumn{2}{|l|}{ whor (rean) } & \multirow{2}{*}{ 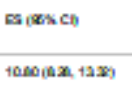 } & \multirow{2}{*}{ 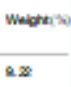 } \\
\hline Solawa a cote & - & & \\
\hline Gubater a a 00050 & $\rightarrow$ & $\sec \left(x \sin x T_{2}\right)$ & ase \\
\hline Hosa a a poth & - & $T 20(3+28+16)$ & $2 x$ \\
\hline Gentin et $x(x+5)$ & $\rightarrow$ & 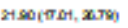 & $a x$ \\
\hline 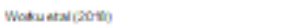 & \pm & $\operatorname{sen}(422 \pi T 20)$ & 20 \\
\hline Nens a a (2005) & $\rightarrow$ & 02010251020 & $2 x$ \\
\hline Datocis a a $(2000)$ & • & $2+0(0 \mathrm{Ta} 24)$ & 20 \\
\hline DU:a $(2057)$ & نُبــ & 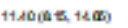 & $2 \alpha$ \\
\hline Ameinat at $x(x+1)$ & - & $200(\pi+a+220)$ & $2 x$ \\
\hline tumb a 4 (2009) & & tetopest, exs) & ax \\
\hline Wigunibat $x(x+8)$ & - & $1580(8)=011)$ & $2 x$ \\
\hline 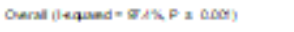 & & $12 \cos (\theta \pi, 14 \pi)$ & 10000 \\
\hline 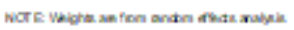 & & & \\
\hline
\end{tabular}

\section{Figure 2}

The Forest plot the level of Knowledge(A), Attitude(B) and Practice(C) Towards Cervical Cancer Screening in Ethiopia, 2019 


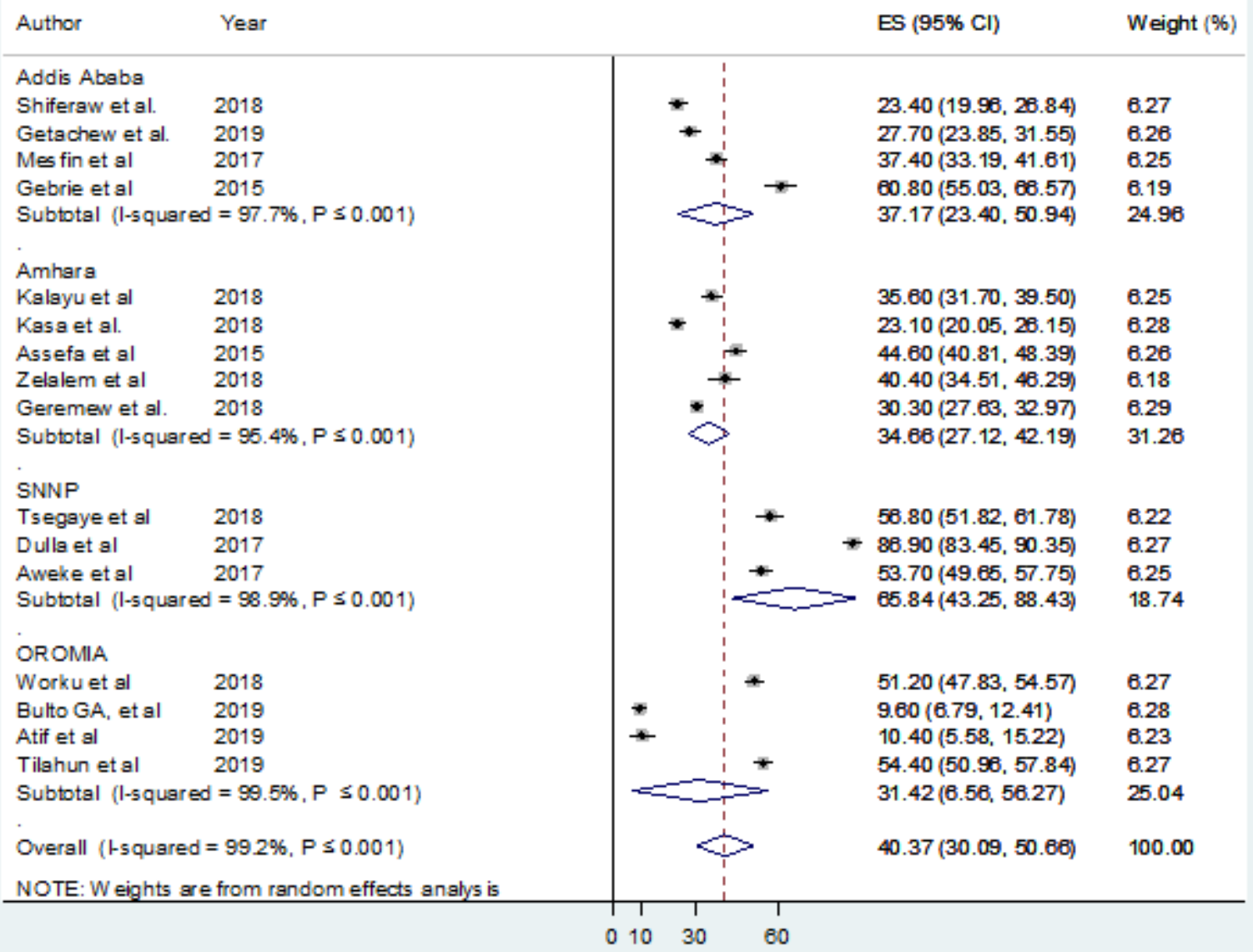

\section{Figure 3}

Subgroup Analysis of knowledge about cervical cancer screening in Ethiopia, 2019. 
A

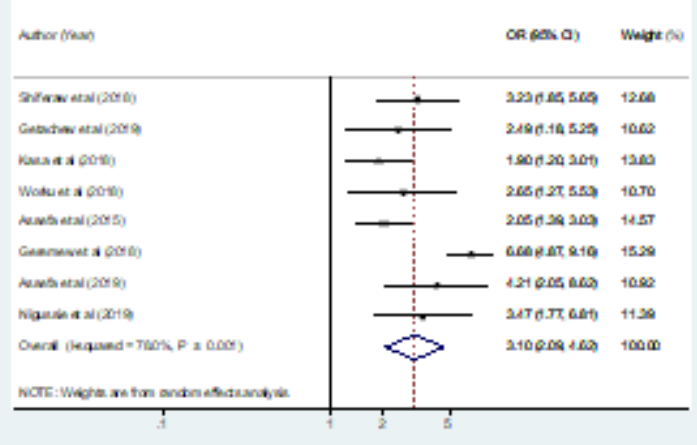

$\mathrm{C}$

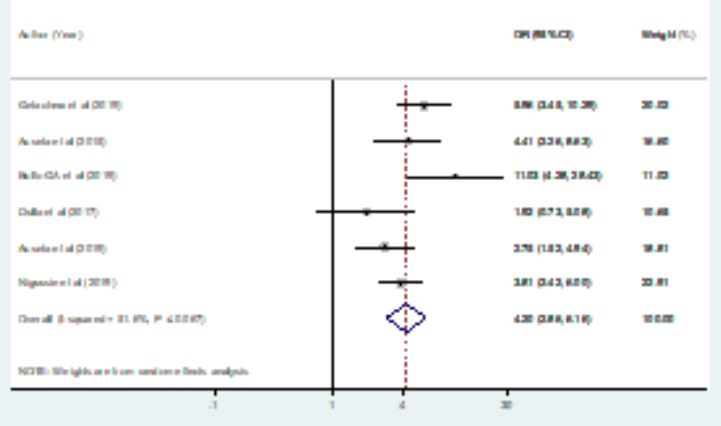

B

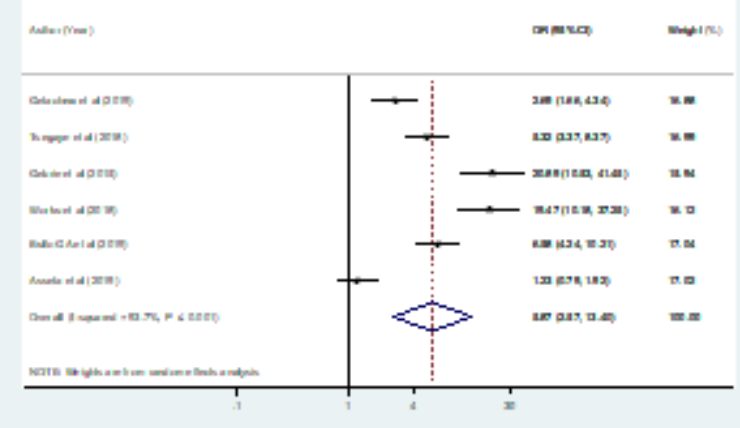

$\mathrm{D}$

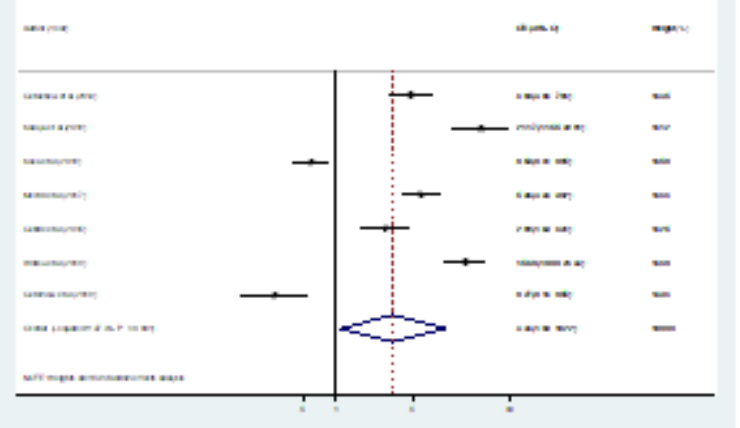

\section{Figure 4}

Associated Factors for practice of screening cervical cancer in Ethiopia, 2019: A) Educational Status, B) Knowledge, C) Attitude, D) Marital Status

\section{Supplementary Files}

This is a list of supplementary files associated with this preprint. Click to download.

- PRISMA2009checklist.pdf 